\title{
High-temperature microwave pyrolysis of peat as a method to obtaining liquid and gaseous fuels
}

\author{
T.O. Krapivnitskaia ${ }^{1,2}$,A.A. Bogdashov ${ }^{1}$, A.N. Denisenko ${ }^{1}$, M.Yu. Glyavin ${ }^{1}$, \\ Yu.K. Kalynov ${ }^{1}$, S.V. Kuzikov ${ }^{1}$, N.Yu. Peskov ${ }^{1}$, L.L. Semenycheva ${ }^{2}$ and A.V. Stricovskiy ${ }^{1}$ \\ ${ }^{1}$ Institute of Applied Physics RAS, Nizhny Novgorod, Russia, kto465@yandex.ru \\ ${ }^{2}$ Lobachevsky State University of Nizhniy Novgorod, Nizhny Novgorod, Russia
}

Currently, scientific researches and engineering developments in the field of physical-chemical processing of organic raw materials, in particular, aimed on production of so-called renewable liquid and gaseous fuels, are becoming increasingly important. One of the materials that recently attracted high research interest from the point of view of the great variety of its practical applications is a peat [1].

There are various methods of the peat processing; however, the most promising is a high-temperature microwave pyrolysis. The main advantages of microwave pyrolysis over traditional thermal heating systems include the following: high processing efficiency, volume character and high thermal efficiency (up to 90 -95\%) of microwave heating, increase in the speed of chemical and physical-chemical reactions under the action of microwave radiation, possibility to achieve high temperatures and deep processing of biomaterial, high environmental safety, etc.

The installation for the high-temperature peat destruction under the action of microwave radiation was developed at the IAP RAS based on industrial $2.45 \mathrm{GHz}$ / $1 \mathrm{~kW}$ magnetron (Fig. 1).
In the recent series of experiments, optimization of the electrodynamic system transportating radiation from the magnetron into the interaction vessel (reactor) was carried out. To reduce thermal loads on the barrier window an additional cooled waveguide section was installed for condensation of the resins products of the processing. Tuning waweguide elements were added to keep high transmission of the radiation into the reactor during radical change of the absorption capacity of peat in the process of high temperature treatment [2].

The first series of experiments on this installation was carried out. As a result of high-temperature peat pyrolysis, an oily fraction, a carbonaceous residue and a pyrolysis gas were obtained. A series of experiments was also carried out using traditional thermal heating of peat. The obtained samples were analyzed on GCMS-QP2010 Ultra-GC-mass spectrometer. Chromatograms of pyrolytic gases were compared and showed a higher yield of combustible gases when microwave exposure to samples (Fig. 2, 3).

A CH-analysis of the initial sample loaded into the reactor and a carbonaceous residue after the pyrolysis process were also carried out (Table 1).

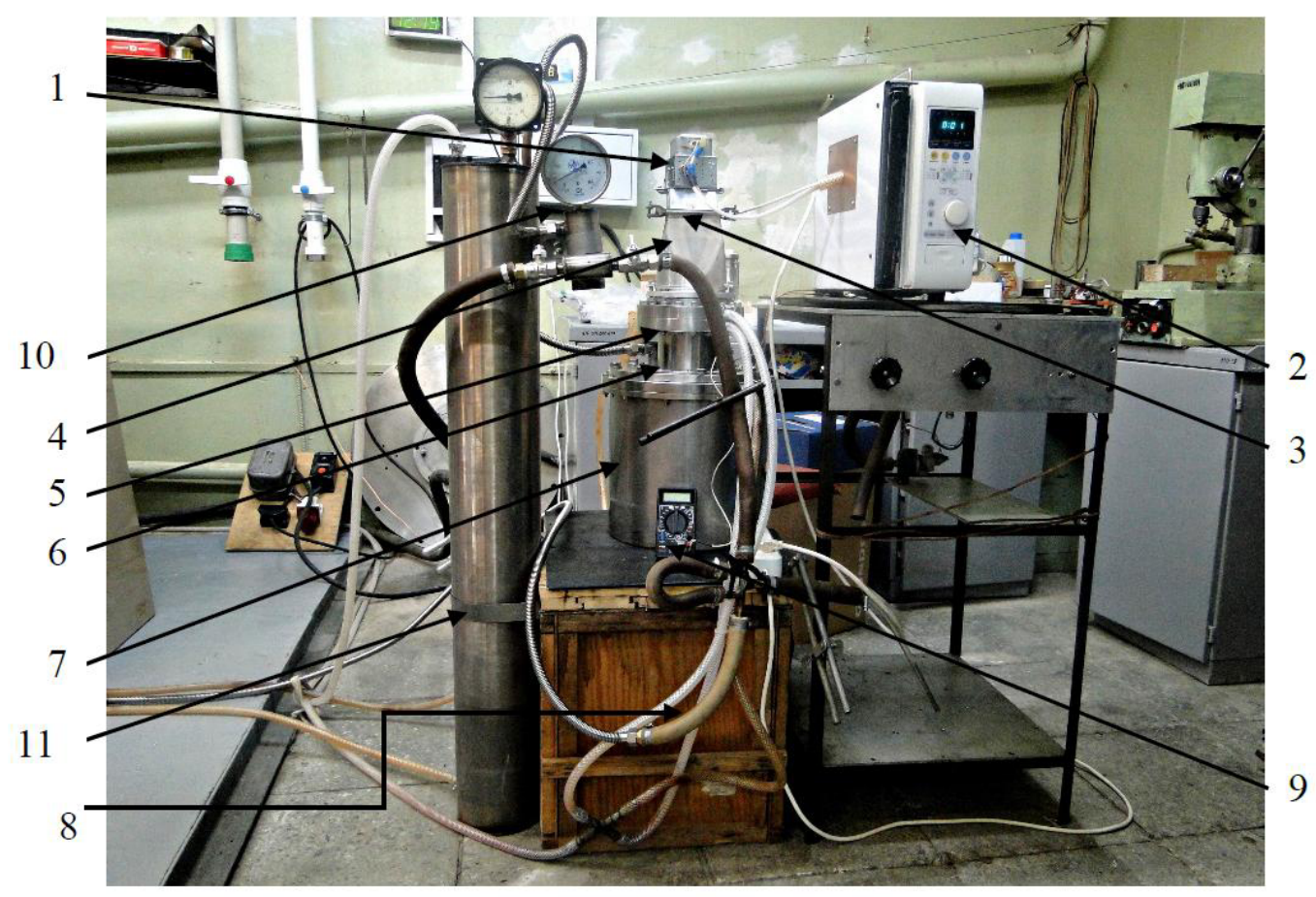

Fig. 1. Photograph of experimental test facility for peat pyrolysis heated by microwave radiation:

1 - industrial magnetron; 2 - power supply system; 3 - air cooling system; 4 - matching wave-guide elements; 5 - barrier window; 6 - connection waveguide; 7 - operating camera; 8 - water cooling system; 9 - thermoelectric couple; 10 - pressure-gauge; 11 - the heat exchanger 


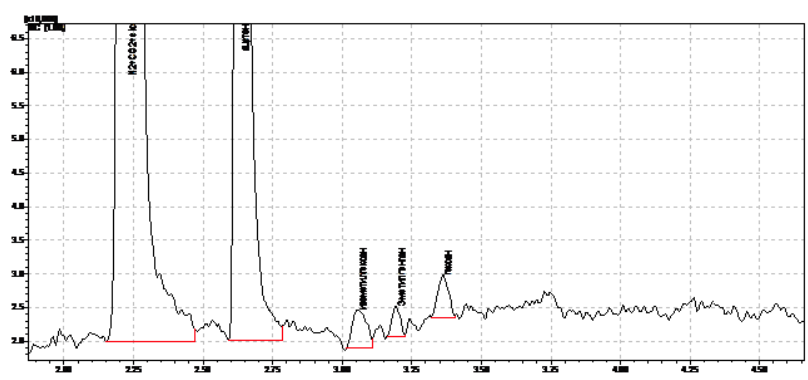

Fig. 2. Chromatogram of pyrolysis gases during thermal heating

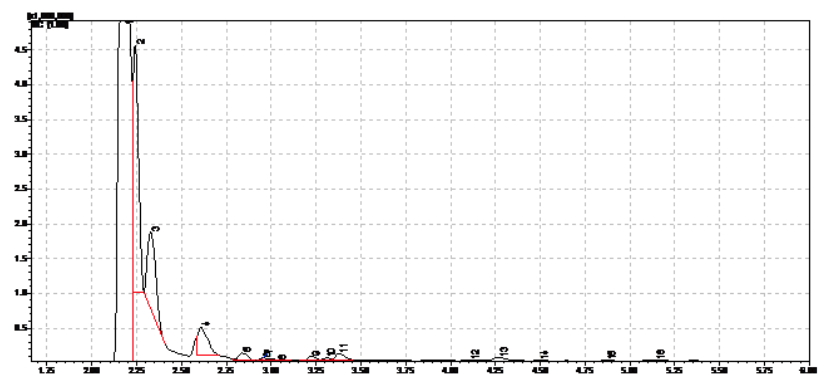

Fig. 3. Chromatogram of pyrolysis gases at microwave heating

The mass fraction of carbon in percent after processing the sample with microwave radiation was more than 2 times greater than the mass fraction of carbon in the initial sample [3]. According to the initial results of the analysis of the samples, it can be said that the proposed peat processing method is more effective than traditional heating methods and allows to significantly increase the rate of pyrolysis process passage, as well as to increase the yield of combustible gases for their further application. As further development of work on microwave pyrolysis, an increase in the efficiency of the output of combustible gases from organic fuel and, thus, the efficiency of the installation, as well as the possibility of creating a closed cycle for powering the device and its autonomous operation.

A prospective set of applications under development currently is related to RF impact on biological objects including the microwave grain crop drying in order to eliminate the fungal contamination, RF methods for lumber disinsectization and destruction of pest, etc.

Preliminary basis allows to make a conclusion on the prospective of using the microwave radiation in technological processes, in an increasingly large number of applications and on economic advantages of this approach.

Table 1. The results of $\mathrm{CH}$-analysis

\begin{tabular}{|l|c|c|c|c|}
\hline \multicolumn{1}{|c|}{ Name } & $\omega(\mathrm{C}), \%$ & $\omega(\mathrm{H}), \%$ & $\omega(\mathrm{N}), \%$ & $\omega(\mathrm{S}), \%$ \\
\hline initial sample & 31 & 7,9 & 0,52 & $<0,3$ \\
\hline $\begin{array}{l}\text { after micro- } \\
\text { wave } \\
\text { processing }\end{array}$ & 64,28 & 5,02 & 1,4 & $<0,3$ \\
\hline
\end{tabular}

\section{References}

1. J.Yang, H.Chen, W.Zhao, J.Zhou. TG-FTIR-MS study of pyrolysis products evolving from peat // Journal of Analytical and Applied Pyrolysis. № 117, 296-309 (2016)

2. M.Yu.Glyavin, Y.K.Kalynov, T.O.Krapivnitskaia, et.al. Development of microwave test facility for peat pyrolysis // Proc. of the 26th Int. Conf. "Microwave and Telecommunication Technology" (CriMiCo 2016), Sevastopol, Russia, 2016, 10, 2287-2293

3. T.O.Krapivnitskaia, N.Yu.Peskov, L LSemenycheva, et al., Perspective applications of high-power microwave radiation in problems of exposure to organic materials and biological objects // Proc. of the VI All-Russian Scientific and Technical Conference "Electronics and Micro-electronics Microwave", St. Petersburg, Russia, impress. 